\title{
10 years of joint research at DLR and TU Braunschweig toward low-noise aircraft design-what did we achieve?
}

\begin{abstract}
This review article is based on an invited keynote presentation at the 22nd Workshop of the Aeroacoustics Specialists Committee of the CEAS. The event was held in September 2018 in Amsterdam with the main focus on the relation between aircraft design and noise impact. This article reviews the last years of joint research activities between the German Aerospace Center (DLR) and the Technical University of Braunschweig (TU BS) in the field of low-noise aircraft design. The joint research was initiated around 2008 between the DLR Institute of Aerodynamics and Flow Technology and the Institute of Aircraft Design and Lightweight Structures at TU BS. Around that time, DLR was developing a first version of an aircraft noise prediction tool. This tool has then consequently been implemented as a module into the aircraft design synthesis code of the TU BS. In 2012, for the first time, a fully automated and fully parametric aircraft design process with integrated noise prediction capabilities was established, i.e., including a full approach and departure flight simulation. The main focus lies on conventional tube-and-wing aircraft with turbofan or turboprop engine concepts. Ever since 2012, the tools have been under constant development and the simulation chain for low-noise aircraft design has been applied to various aircraft concepts. This article is comprised of a description of the tool development from 2008 until early 2018 and a selected application example. Some lessons learned and a brief outlook on future developments and applications conclude this review.
\end{abstract}

Volume 3 Issue 2 - 2019

\author{
Lothar Bertsch,' Wolfgang Heinze, ${ }^{2}$ Sebastien \\ Guerin, ${ }^{3}$ Markus Lummer, ${ }^{4}$ Jan Delfs ${ }^{5}$ \\ 'German Aerospace Center (DLR), Institute of Aerodynamics \\ and Flow Technology, Gottingen \\ ${ }^{2} \mathrm{TU}$ Braunschweig (TU BS), Institute of Aircraft Design and \\ Lightweight Structures, Braunschweig \\ ${ }^{3}$ German Aerospace Center (DLR), Institute of Propulsion \\ Technology, Berlin \\ ${ }^{4}$ German Aerospace Center (DLR), Institute of Aerodynamics \\ and Flow Technology, Braunschweig \\ ${ }^{5}$ German Aerospace Center (DLR), Institute of Aerodynamics \\ and Flow Technology, Braunschweig
}

\section{Correspondence: Lothar Bertsch, German Aerospace Center (DLR), Institute of Aerodynamics and Flow Technology, Gottingen, Germany, Email Lothar.Bertsch@dr.de}

Received: May 08, 2019 | Published: May 31, 2019

\section{Nomenclature}

Quantities

\section{BPR bypass ratio}

$\Delta \mathrm{h} \quad$ relative distance of noise source to observer location, $[\mathrm{m}]$

$\Delta \mathrm{L} \quad$ level difference, $[\mathrm{dB}]$

EPNL effective perceived noise level, [dB]

I sound level intensity, [dB]

$\mathrm{L}_{\text {Aeq }} \quad$ time-weighted, equivalent continuous sound pressure level, $[\mathrm{dB}]$

$\mathrm{L}_{\mathrm{A} ; \max } \quad$ maximum, A-weighted sound pressure level, [dB]

SEL sound exposure level, $[\mathrm{dB}]$

$\mathrm{V} \quad$ flow velocity, $[\mathrm{m} / \mathrm{s}]$

Abbreviations: CEAS, Council of European Aerospace Societies; DLR, German Aerospace Center; Empa, Swiss Federal Laboratories for Materials Science and Technology; ICAO, International Civil Aviation Organization; PANAM, Parametric Aircraft Noise Analysis Module, DLR noise prediction tool; PrADO, Preliminary Aircraft Design and Optimization, TU BS aircraft design synthesis code; SHADOW, DLR tool for noise shielding calculation; TU BS, Technical University of Braunschweig, Germany

\section{Introduction}

Several non-technical and technical measures to fight aircraft noise have been formulated by the International Civil Aviation Organization (ICAO). ${ }^{1}$ The so-called ICAO "Balanced Approach" is derived from the definition of the time weighted, equivalent continuous sound pressure level $\left(\mathrm{L}_{\text {Aeq }}\right)$.

$$
L_{\text {Aeq }}=10 \cdot \log _{10}\left(\frac{1}{T} \sum_{i=1}^{N} g_{i} \cdot 10 \frac{S E L_{i}}{10}\right)
$$

This equation yields the $\mathrm{L}_{\mathrm{Aeq}}$ at one location within a characterization time T, e.g., $\mathrm{T}$ could be selected as all calendar days within one year. Simulated $\mathrm{L}_{\mathrm{Aeq}}$ at multiple locations around an airport can directly be translated into isocontour areas and so-called noise protection zones. ${ }^{2}$ The predicted level at an arbitrary ground location is directly affected by the so-called non-technical ICAO measures (number of flight events $\mathrm{N}$ and time weighting $\mathrm{g}_{\mathrm{i}}$ of each flight "i") and the so-called technical ICAO measures (sound exposure level SEL for each flight "i"). These measures have to be applied and assessed at the same time according to ICAO. In 2007, prior to the joint research activity of the German Aerospace Center (DLR) and the Technical University of Braunschweig, no simulation process had been known to the authors that would allow to investigate the technical measures of the ICAO "Balanced Approach" in sufficient detail, i.e., also allowing to assess new technologies or novel vehicle concepts. Aircraft design synthesis processes were available since decades but did not include noise prediction capabilities. Available ideas toward low-noise aircraft concepts had not been subject to a complete noise immission assessment. It can be summarized, that in 2007 many ideas toward lownoise aircraft concepts had been published, yet the methods to assess the corresponding noise immission along a flight procedure were not available. Consequently, available concepts were not the result of any large design study or parameter variation hence would not represent optimal solutions. Consequently, the focus of the presented research activities of DLR and TU BS was a simulation process for the detail assessment of aircraft design and flight procedure. A new process had 
to be developed in order to apply and assess these technical ICAO measures simultaneously. Although the process was developed to assess ICAO's technical measures, it is of course applicable to assess the remaining non-technical measures as well.

Several tools for overall aircraft noise prediction were available and documented in the literature in 2007 , e.g., INM ${ }^{3}$ or NASA's ANoPP. ${ }^{4,5}$ Depending on their origin and their core area of application, available tools have been separated into two categories, i.e., the "best-practice simulation tools" and the "scientific simulation tools" (e.g., definition according to Ref. ${ }^{6}$ ). The "best-practice" tools work with extensive correlations of measurement data and are therefore not directly applicable to assess novel technology. Moreover, "bestpractice" tools simulate the overall aircraft as one noise source which is in direct contrast to any novel technology that can usually only be associated with a certain individual noise sources or mechanism. By simply subtracting a constant delta level from the (measured) overall aircraft noise emission in a database, individual modifications to certain noise source can obviously not be captured. Only "scientific simulation tools" with a detailed parametric modeling of each source mechanism can be applied to investigate how aircraft noise immission is affected by novel technology, flight path modification, ${ }^{1}$ and/or vehicle design.

In 2007, available and known research activities in the context of "scientific simulation tools" were associated with one or more of the following shortcomings. First, the acoustics was not available as a design constraint within the aircraft design phase. Only a subsequent noise assessment of predefined and already final concepts had been available. Consequently, no design variations or optimizations were possible and the solution space was very limited from the beginning. The second shortcoming had been the incomplete consideration of relevant disciplines or interactions. For example, modifications to certain aircraft or engine noise components to reduce noise were assumed without consideration of the impact on other aircraft disciplines and on the overall flight performance. The third significant shortcoming had been the insufficient assessment of the problem. Often, the known and published results were associated with one or a combination of the following limitations. The noise assessment was limited to the emission situation, to a certain aircraft component, to a specific noise metric only, to certification noise levels, and/or to a fixed operating condition. These limitations prevented the identification of optimal solutions, could falsify conclusions due to inadequate metric or problem definition, and most certainly could result in solutions that are not valid during varying operating conditions along any realistic flight with its corresponding noise source ranking.

\section{Motivation}

In 2008 it was decided to join forces of DLR and TU BS in the field of aircraft design and noise prediction. The TU BS is known for their aircraft design process PrADO,$^{7-9}$ whereas DLR brings its methods, data, and expertise in flight simulation, engine design, and comprehensive aircraft noise prediction to the table. The overall goal was defined as a joint simulation process for low-noise aircraft design. Based on the status quo as described in the introduction, certain main requirements toward such a novel simulation process were defined.

It was decided that a reasonable low-noise design process would require the following characteristics:

${ }^{1}$ This is especially important if a typical approach with its varying noise source dominance is evaluated. a) All relevant noise sources and major interaction effects are taken into consideration.

b) Individual noise sources and their contribution to the overall vehicle noise - a.k.a. noise source breakdown or noise source ranking - are specifically assessed under varying operating conditions.

c) Emission situation and immission along fully detailed approach and departure procedures are evaluated, i.e., again under varying operating conditions.

d) Multiple noise metrics at different and widespread ground locations have to be considered.

e) Noise prediction has to be incorporated as early as possible in the aircraft design process, i.e., within the conceptual aircraft design phase.

The last characteristic is of utmost importance. Only within the conceptual design, relevant aircraft design parameters, e.g., engine selection and engine installation onboard, can be influenced according to a chosen low-noise constraint. By definition, these basic design parameters are determined in the conceptual design phase and then have to be kept fixed through all subsequent design phases. Yet, these parameters have a direct and major influence on the noise generation of the final vehicle, i.e., certain design constraints directly define the acoustic performance of the vehicle. Exemplary design parameters and the overall influence on the noise generation of corresponding components or the overall aircraft are shown in Figure 1. Several major design parameters can be directly assigned to the sound intensity I of certain components or the overall vehicle. Consequently, a direct integration of noise prediction within the design process has been the main goal of a joint research activity.

The development of the overall simulation process is described in the next section. After a selected application example, the article is concluded by a summary with lessons learned and a brief outlook section.

\section{Simulation process}

This section about the simulation process is divided into three chronological working periods, i.e., "bringing the disciplines together" (2007-2008), "toward a fully automated low-noise design process" (2009-2012), and "focus on noise immission" (2013-early 2018). Each description is initiated with a timeline of major developments and applications and is concluded with a status overview of the simulation process at the end of each working period (Figure 2, 3 and 5). An overview chart with all developments and applications (including corresponding literature references) is provided in the Appendix (Figure 5).

The description of the first working period starts with a brief status quo at DLR and TU BS in the year 2007. Inspired by known research activities and available publications, e.g., Ref., ${ }^{10}$ the cooperation of DLR and TU BS was initiated in 2008. It is demonstrated how the related disciplines, i.e., mainly aircraft design and noise assessment, were brought together as described in Refs. ${ }^{11,12}$ The second working period dealt with developments between 2009 and 2012 leading to an automated aircraft design process as described in Refs. ${ }^{6,13-22}$ The third working period started in 2013. It included additional updates and upgrades to the process toward its current status with the focus on noise immission in early 2018, see Refs. ${ }^{23-39}$ 


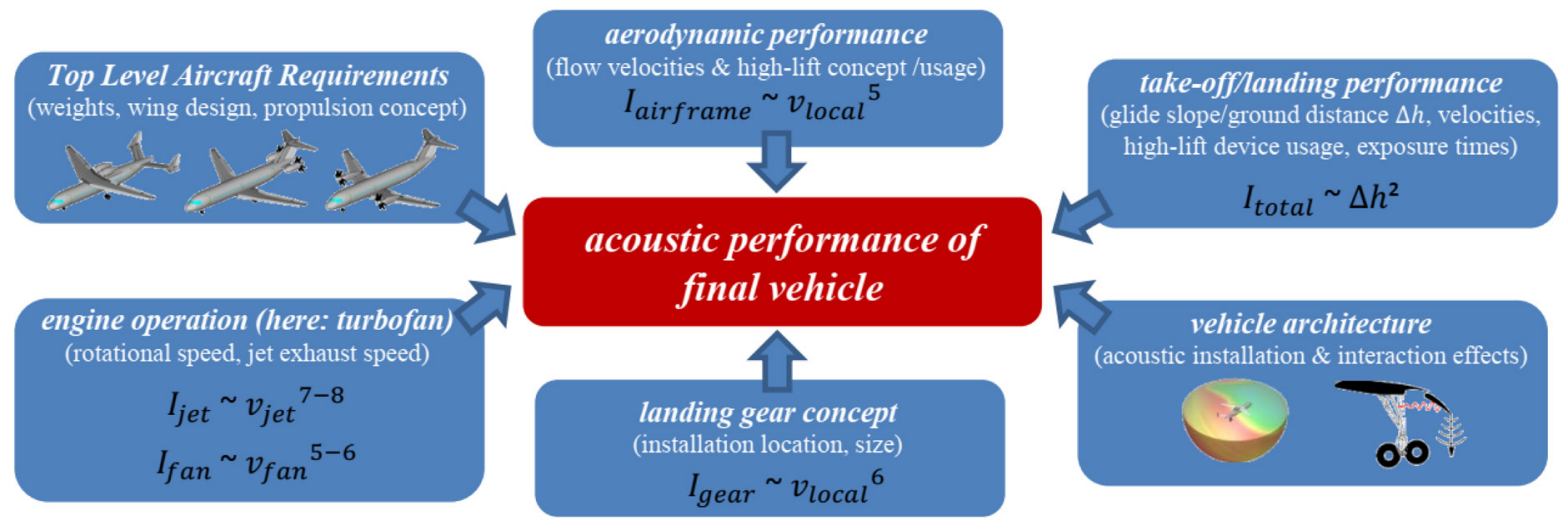

Figure I Influence of aircraft design on the final vehicle's acoustic performance.

\section{8 - "bringing the disciplines together"}

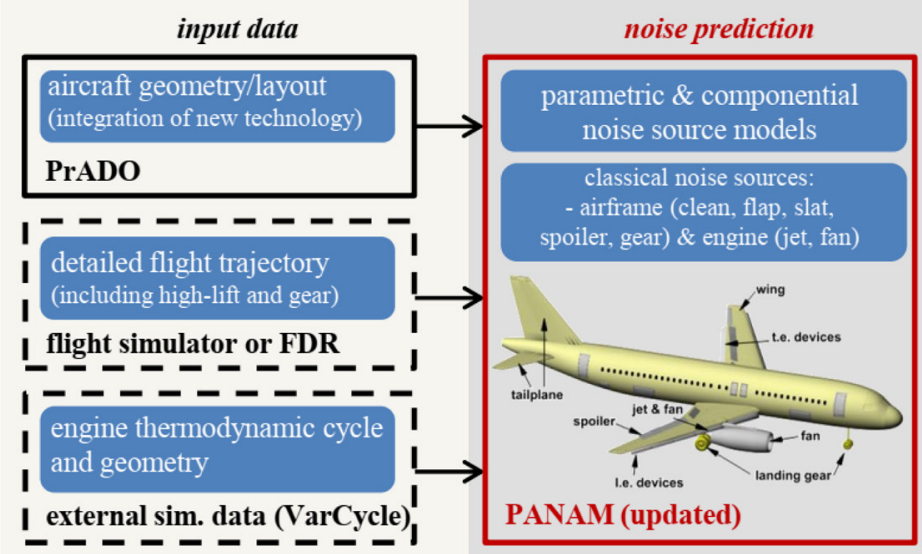

status

tube-and-wing $\mathrm{a} / \mathrm{c}$ with turbofan engines

- external data required: flight path and engine

- processing of (mainly) external input data

\section{application examples}

reference vehicle A319-100

- PrADO design, measured flight

trajectories, external engine simulation

comparison with measured noise levels of A319-100: $L, L_{A}, S E L, E P N L$

- simulation of real time noise contours

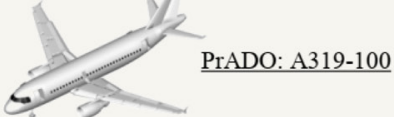

Figure 2 Status of simulation capability in 2008 (first year of joint research).

\section{2 - "fully automated low-noise design process"}

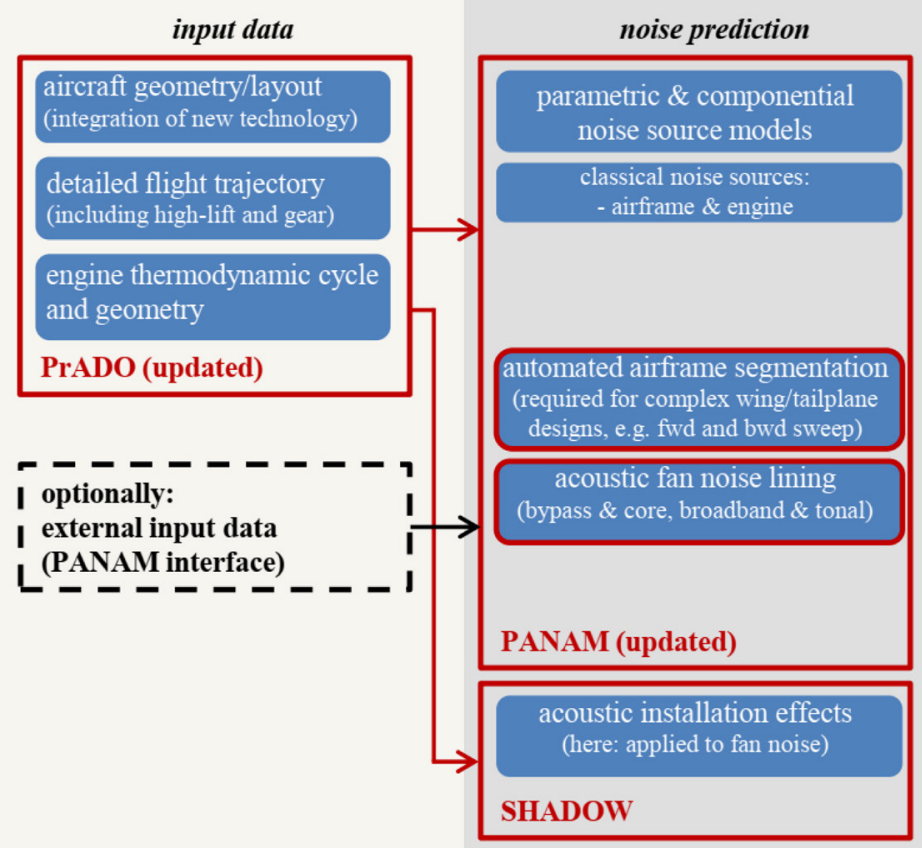

status

installation effects \& acoustic lining

automated process (required input available)

focus on source emission with subsequent

immission prediction (design-to-noise)

\section{application examples}

low-noise aircraft design study

- focus on fan noise shielding

- 500 aircraft variants along standard approach \& departure flight

- preferred engine installation:

above wing/fuselage

junction

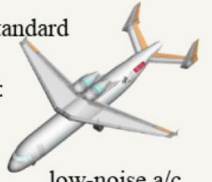

low-noise approach procedures

- procedure definition \& flight test preparation (DLR ATTAS a/c)

- steep and helical approach

procedure

low-noise approach

Figure 3 Status of simulation capability in 2012 .

Citation: Bertsch L, Heinze W, Guerin S, et al. 10 years of joint research at DLR and TU Braunschweig toward low-noise aircraft design-what did we achieve? Aeron Aero Open Access J. 2019;3(2):89-104. DOI: 10.15406/aaoaj.2019.03.00085 


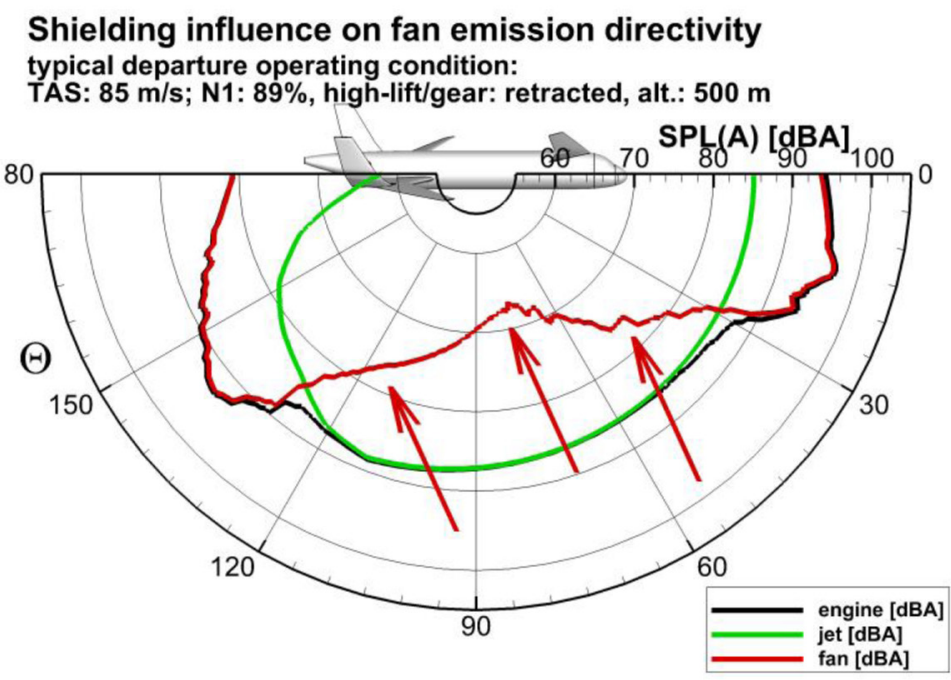

Figure 4 Fan noise shielding on board of the DLR Low-Noise Aircraft (LNA).

2017 - "focus on noise immission"

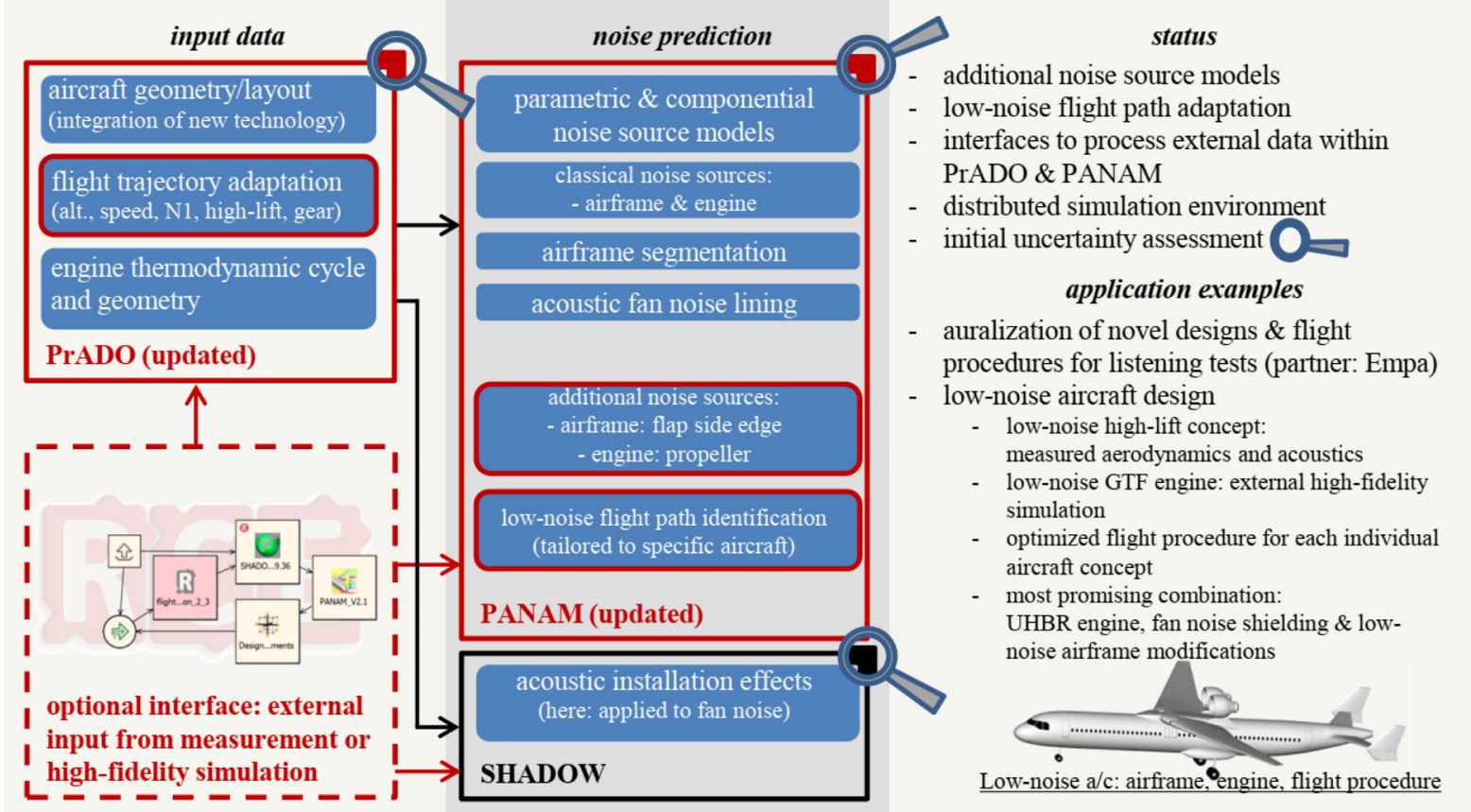

Figure 5 Status quo of simulation capability (early 2018).

\section{“Bringing the disciplines together" (2007-2008)}

In 2007 DLR has released a first version of a comprehensive aircraft noise prediction tool referred to as Parametric Aircraft Noise Analysis Module (PANAM) and introduced in Ref. ${ }^{11}$ The main feature of this prediction tool is the capability to predict the overall aircraft immission as a combination of individual noise sources under consideration of moving source and sound propagation effects. Furthermore, the predictions account for both operational input parameters and for aircraft and engine design related input. Therefore, appropriate parametric models for relevant individual noise sources were selected and finally incorporated into the tool. The models capture the most relevant physics-related effects based on available input data of adequate complexity.

The selected airframe noise source models come from DLR and are described in Refs. ${ }^{40-45}$ in more detail. The airframe of the initial PANAM version was comprised of clean wing, flap, slat, spoiler (fully empirical), and landing gear contribution. The engine noise of conventional turbofan engines can adequately be described by its two dominating noise sources, i.e., fan and jet noise. For both contributions, the most commonly accepted models were selected. Fan noise is described with the Heidmann fan noise model according to Ref. ${ }^{46}$ with some modified coefficients to capture the 2007 status quo of fan design and related technologies. The jet noise is modeled 
with a method by Stone according to Ref. ${ }^{47}$ Simple models for the noise generation in the engine core, e.g., combustion noise, were available but not accounted for due to the strong dominance of jet and fan on overall engine noise. Future reduction of now dominating noise sources will ultimately increase the influence of these neglected noise sources. Therefore, PANAM has a modular setup allowing for a straight-forward implementation of new or revised source models. The resulting computational costs of the initial PANAM version are well suitable in the context of multiple design iterations within a large simulation process (Figure 2).

All selected source models have in common that the predicted noise emission is defined by operational and geometrical parameters, which can be subject to a low noise parameter trade study. Obviously, the input parameter requirement depends on the selected noise source models and this input has to be known in order to initiate a noise prediction. For PANAM the input data can be assigned to the following groups: aircraft design parameters, engine design and performance parameters, operating conditions, i.e., flight data, and parameters describing the scenario (flight track routing and selection of observer locations). All of the required input can be user specified, based on measurements, and/or be generated by external simulation tools, i.e., often high-fidelity simulation tools. The scenario settings are selected by the user and defined according to the application scenario, e.g., reproduction of a measurement setup for the comparison of prediction versus measurement.

The immission results of the prediction process are comprised of the standard metrics, e.g., SPL, EPNL, or SEL, at arbitrary and scenario-specific observer arrangements. In addition to these noise immission results, the results of all preceding simulation steps can optionally be stored and further processed, e.g., for an investigation of noise emission from specific sources along a simulated flight. The results of preceding simulation steps include the time history of each predicted level, i.e., the emission or immission of arbitrary noise sources or a combination of sources can be animated over time. ${ }^{11}$

As stated in the motivation section, the overall goal of the joint research is the direct integration of the aforementioned noise prediction as a simulation module within an adequate aircraft design process. Such a modular process was available at the TU BS (without consideration of noise), i.e., the Preliminary Aircraft Design and Optimization code (PrADO). ${ }^{7-9}$ PrADO is a design synthesis code that enables an iterative execution of task-related design modules until predefined design variables have reached convergence. The individual modules operate with a common data base and can straightforwardly be replaced by modules of higher fidelity that address the identical task or discipline. The 2007 version of PrADO had to be updated so that the required basic input for a noise prediction with PANAM could have been generated. Yet, not all input parameters as required by the noise source models were available within the aircraft design process at that point. Missing parameters or data of inadequate quality for the noise prediction had to be manually processed from external data sources. Pre-computed engine data was provided from external highly-specialized tools, e.g. DLR tool Varcycle. ${ }^{48}$ The flight data was not generated within the simulation process at that time but also had to come from external sources. Data was extracted from a ground-based flight simulator ${ }^{49}$ in order to realize a first PANAM comparison with actual fly-over measurements. ${ }^{11}$ The 2008 comparison demonstrated a satisfying agreement between measurements and predictions.

Bringing together the disciplines aircraft design and noise prediction allows to directly identify the parameters that have the most significant impact on the noise immission. These parameters can then be modified under consideration of the implications on all other disciplines within the design process. A feasible and reliable conclusion can now be made because all relevant implications, i.e., socalled snowball effects, are accounted for. Low computational costs of any of these noise source models allows for a quick overall assessment and large parameter variations which can ultimately be combined into a low-noise design optimization. The status of the initial simulation process in the first year of the cooperation is depicted in Figure 2, i.e., modifications to the 2007 PANAM Version are highlighted in red color. At this point, external input data was an essential requirement to execute the simulation, i.e., the flight path (extracted from a ground-based flight simulator run or from the flight data recorder) and the engine data (external simulation tool Varcycle ${ }^{48}$ ). The initial application was a reproduction of a DLR fly-over noise campaign so that predictions could be compared with actual measurements along the approach and flight procedures.

\section{"Toward a fully automated low-noise design process" (2009-20I2)}

The initial process was constantly upgraded between 2009 and 2012. The status of the 2012 simulation process is depicted in Figure 3 and modifications to the 2008 status are highlighted in red color. The major developments and applications are presented in Appendix (Figure 5). Most importantly, PrADO had to be upgraded in order to generate the required input data for a PANAM computation and to avoid the need for additional and external input data, i.e., especially the recorded flight trajectory. Consequently, a new flight simulation module was developed to account for the specific aircraft flight performance along approach and departure, i.e., resulting in a simplified but physics-based flight path for arbitrary PrADO concepts. Aircraft specific engine settings and angle of attack are adapted along a fixed and predefined altitude and velocity profile. Consequently, the flight trajectory was no fixed input anymore but would reflect the underlying flight performance of the aircraft under investigation. The update made the process directly applicable to modified or new aircraft designs by simply replacing the previously required flight data by simulated data. According to the specific flight performance, an individual approach and departure flight was simulated and a noise prediction along both flights was initiated.

The capability to assess noise immission beyond the defined certification situations was an important requirement in order to enable a more realistic picture of the community noise exposure. Multiple acoustic metrics at arbitrary observer locations and arrays were considered. Yet, due to the simplicity of the module, no investigation of low-noise flight trajectories was possible at that time but a predefined procedure was simulated.

The second major upgrade was related to the engine simulation. The PrADO thermodynamic cycle of the engine was improved to yield the required input parameters for PANAM, e.g., the jet exhaust velocities and temperatures. Furthermore, a simple approximation of the fan rotational speed under defined operating conditions was included based on basic fan design parameters. ${ }^{13}$ This update allowed the simulation of different engine concepts. Yet, if high-quality engine performance data was available for an existing engine, it was preferred over the conceptual design data for the noise prediction.

Automatically generating the required input parameters for an arbitrary aircraft within PrADO significantly enhanced the applicability compared to the initial process as depicted in Figure 
2. In addition to the aircraft geometry, the corresponding flight trajectory and the required engine data could now be generated within each simulations run. Whereas the initial process had been limited to reproducing an existing and measured case, i.e., noise prediction of preselected aircraft along a recorded flight path, the upgrade in 2009 enabled a simulation and variation of any of the required input parameters. This is reflected by application of the process towards the design and the overall evaluation of a quiet short take-off and landing vehicle concept. ${ }^{14,15}$

Around 2010, a new tool was implemented into the process, DLR's shielding tool SHADOW. ${ }^{50,51}$ The tool can be applied to investigate the acoustic shielding due to engine installation effects, i.e., the noise source is not affected but the sound radiation to relevant emission angles can be reduced. The first application of the shielding assessment was the noise prediction of DLR's former flying testbed ATTAS. The aircraft is subject to engine noise shielding with its engines mounted over the wing. The ATTAS was simulated along a newly developed noise abatement flight procedure, the so-called Helical Noise Abatement Procedure (HeNAP). For this study, the noise prediction tools were embedded in a distributed simulation environment in order to combine the noise prediction with an external high-fidelity flight simulation tool. ${ }^{17}$ This computational investigation finally led to a flyover noise campaign during which the predicted noise level reductions and dislocation was demonstrated..$^{18}$ Overall, integration of SHADOW into the process significantly increased the applicability of the process toward more unconventional vehicle designs with prevailing noise shielding effects. Exemplary, the shielding effect on the fan noise emission directivity on board of the DLR Low-Noise Aircraft (LNA) is depicted in Figure 4. Currently, interfaces to shielding tools of even higher fidelity are discussed due to recent success in developing and applying these advanced tools toward overall aircraft noise assessment, e.g., see Ref. ${ }^{52}$

To readily investigate novel concepts with more complex airframe architectures, e.g., multiple tailplanes, another upgrade to the simulation process had become necessary in 2010 . The previous airframe definition by representative geometries, i.e., averaged wing, control surface, and high-lift elements, was no longer applicable. An automated segmentation was implemented in PrADO to separate the lift and control surfaces into acoustical relevant segments. This acoustical segmentation directly generates the required parameters for a PANAM noise prediction of arbitrary and novel airframe architectures.

Ultimately, the three upgrades (flight simulation, engine deck, airframe segmentation) and the SHADOW implementation resulted in an automated and fully parametric aircraft design process with integrated noise prediction capabilities. ${ }^{19}$ Such an embedded noise prediction within the conceptual design enabled the direct comparability of various vehicle concepts including the acoustics at an adequate level of complexity and detail. The process was applied to investigate new ideas ranging from air traffic routing to low-noise aircraft design as described in the literature. ${ }^{20-22}$

\section{“Focus on noise immission” (20/3-early 20/8)}

During this third report period, the simulation process as depicted in Figure 3 has been further developed. Modifications to the 2012 status are highlighted in red color. Interfaces to external aerodynamic input data were defined and continuously implemented into both PrADO (aerodynamics and weights) and PANAM (acoustics).
Based on dedicated model-scale experiments and high-fidelity simulation, the effect of novel low-noise high-lift elements on the overall aircraft flight performance and acoustics were then evaluated. ${ }^{23,24}$ Later during the third period, the interfaces were updated to also account for external engine data from high-fidelity simulation. ${ }^{35}$ The external engine geometry and performance data could now directly be processed within PrADO in order to evaluate the impact on the aircraft design and flight performance. At this point, all required input parameters for a noise prediction could be generated within the simulation process.

During early applications of the process it became obvious, that the proposed design-to-noise methodology might not lead to an optimal solution. Detailed modifications to individual components only showed a benefit if these components were dominant with respect to other noise sources. Consequently, it was decided that the main focus of a feasible low-noise activity needs to be shifted from improving noise emission-with subsequent immission assessment only-to a direct immission assessment. Furthermore, it was decided that the assessment should not be limited to the aircraft noise certification locations, e.g., cf. assessment by NASA in $2015 .{ }^{53}$ The overall aircraft noise as received on the ground ${ }^{26}$ can only be effectively reduced based on a direct immission assessment. Interfaces to a TU Delft/ NLR activity of aircraft noise Auralization were defined in order to investigate and better understand the noise immission situation. ${ }^{27}$ Similar concepts have been under investigation around that time at RWTH Aachen ${ }^{54}$ and at NASA. ${ }^{55}$ Up to 2015, all interfaces were updated in order for PANAM to remain an embedded simulation tool in DLR's continuously improving distributed simulation framework Remote Component Environment ${ }^{2}(\mathrm{RCE})$, later described in Ref. ${ }^{25}$ Furthermore, additional noise source models were implemented into PANAM for application toward different vehicle concepts, i.e., a flap side edge model ${ }^{28,56,57}$ and a propeller noise source model. ${ }^{58}$

The initial PrADO module for approach and departure flight simulation as described previously was replaced by an advanced version, see Ref. ${ }^{33}$ With this replacement, it became possible to identify tailored flight procedures for each individual aircraft, i.e., including the noise relevant high-lift setting and engine operation along the flights. Controlling the timing of high-lift and landing gear deployment, the angle of attack, and the engine thrust setting allows to come up with more realistic flight procedures. The new module also allows to quickly assess the impact of certain parameters on the noise immission and ultimately allows to define low-noise flight procedures for each individual aircraft as early as within the conceptual design phase. For example, modifying a high-lift system for reduced noise emission might decrease the maximum lift coefficient of the vehicle which would directly result in increased flight velocities during the approach. Obviously, any advantageous effect of a low-noise highlift system would directly be counteracted by this general increase in airframe noise due to a higher flight velocity (Figure 3).

From 2016 on, three specific research topics have been under detailed investigation:

(1) Prediction uncertainty assessment,

(2) Large airport simulation scenarios, and

(3) Low-annoyance aircraft design.

In the context of these new research topics, the Swiss Federal Laboratories for Materials Science and Technology (Empa)

${ }^{2}$ https://www.dlr.de/sc/en/desktopdefault.aspx/tabid-5625/ 
significantly contributes to the ongoing DLR and TU Braunschweig cooperation:

1. Essential requirement for any reliable and comprehensive noise assessment is the understanding of inherent result uncertainties. This is especially important if different simulation tools of varying fidelity and/or experimental results are assembled and translated for an overall assessment. It is essential to determine the influence and reliability of individual part results, e.g., noise emission of one high-lift element that are then further processed and combined with other part results to describe the overall noise immission. A dedicated study has been launched in cooperation with Empa to assess and quantify the uncertainties that are associated with PANAM results. Based on previous work by Schäffer et al. ${ }^{59}$ and Thomann ${ }^{60}$ an uncertainty module has been developed. The overall uncertainties of the predicted noise immission are defined as a combination of input data, modeling, and propagation uncertainty as described in Refs. ${ }^{36,37}$

2. The goal of this research is an overall assessment of selected low-noise technologies and vehicle concepts within large airport scenarios. An initial simulation process of such an overall scenario assessment is defined by a three-staged simulation approach, i.e., the component level, the single aircraft level, and the system scenario level as described in Ref. ${ }^{38}$ The single aircraft level is thereby comprised of the entire simulation process of the DLR and TU BS cooperation as depicted in Ref. ${ }^{3}$ The individual technologies and components are provided from the component level (based on their high-fidelity simulation results), transferred to the single aircraft level (here the technologies and components are installed on an aircraft and the overall noise immission is predicted), to finally integrate the new vehicles into a scenario (the overall noise immission around the airport is predicted according to the scenario, see Ref. ${ }^{61}$ ). Obviously, it was necessary to combine various simulation tools of strongly different fidelity levels in order to enable this overall assessment. High-fidelity computational analysis of specific low-noise technology was transferred down to the overall aircraft design to enable a noise assessment of this individual vehicle on a mid-fidelity level. Thereafter, the individual vehicle on its flight trajectory was implemented into a large airport scenario which furthermore reduced the level of detail and fidelity. The main goal of this activity is to keep as much of the high-fidelity information and physics when reducing overall detail and moving from component to single flight down to the scenario. As a final step, the initial results of this new process still have to be subject to an uncertainty assessment as described previously. At the time of the initial application as described in Ref, ${ }^{38}$ the uncertainty assessment had still been under development.

3. The most recent upgrade and corresponding application of the process as depicted in Figure 5 is low-annoyance or perception influenced aircraft design. Based on initial work on Auralization ${ }^{27}$ and inspired by the groundbreaking work of Rizzi, ${ }^{62}$ a pilot project Impact DrivEn Assessment of Low-noise aircraft (IDeAL) was initiated with Empa. Under Empa lead, Auralizations were performed for several novel DLR aircraft designs along different approach flight procedures as described in Ref. ${ }^{39}$ The resulting sound samples have then been used for listening tests in order to assess the annoyance of the test subjects. A proof of concept was demonstrated (see Ref. ${ }^{39}$ ) and initial results of the listening tests are very promising and scheduled for publication in early 2019.

\section{Selected application example}

A recent study ${ }^{50}$ of 2018 has been selected in order to demonstrate the main simulation capabilities that are available after 10 years of joint research. The main capabilities are the following:

a. aircraft design process with integrated noise assessment

- Assessment along aircraft specific approach and departure flights,

- Application to low-noise (shielded) architectures.

b. processing of external input data from high-fidelity simulation or experiment (incorporated in noise prediction and aircraft design)

- High-lift aerodynamics, weights, and acoustics,

- Engine performance deck and geometry details.

c. uncertainty assessment of prediction results

The focus of that study lies on the engine replacement on board of conventional and low-noise tube-and-wing aircraft architectures. The resulting noise immission is assessed for vehicles with reference versus geared turbofan (GTF) engine concepts. Furthermore, the efficiency of additional low-noise airframe measures is studied for each vehicle concept. Results of this investigation were published in Refs. ${ }^{23,24,35}$ and are now presented here to demonstrate the available simulation capabilities. In addition to what was presented in 2018, the newly developed uncertainty module is applied to the prediction results according to Refs. ${ }^{36,37}$ A direct comparison of the engine replacements, ${ }^{35}$ and a more detailed assessment of level differences due to the modifications including prediction uncertainties are presented. For all predictions, approach and departure flights are considered and all vehicles are simulated along individual and detailed flight procedures.

In a first section, the vehicles and technologies are introduced. A second section discusses the impact of engine replacement on performance and noise immission. And finally, a third section is dedicated to a detailed study of the effect of individual technologies and modifications under consideration of prediction uncertainties.

\section{Vehicles and technologies}

The reference aircraft is referred to as "zero" 35 and is a conventional tube-and-wing aircraft with turbofan engines of bypass ratio (BPR) 6 . The design is based on the following Top Level Aircraft Requirements (TLAR): $4000 \mathrm{~km}$ range, $180 \mathrm{Pax}, 1890 \mathrm{~kg}$ payload and a cruise Mach number of 0.8 . The low-noise aircraft architectures are designed for a reduced cruise Mach number of 0.7 to counteract adverse effects on cruise aerodynamics due to the selected engine integration. This reference vehicle is then subject to certain modifications as depicted in Figure 6, i.e., modifications to the engine (replacement of BPR 6 with BPR 12 engine), the aircraft architecture (aircraft adaptation to BPR 12 engine \& fan noise shielding), and/or the airframe (low-noise high-lift \& low-noise landing gear). For simplicity, the following abbreviations are introduced: "+gtf" for the engine replacement, "+adapt" for the aircraft adaption to the new engine, "+shield" for the fan noise shielding architecture, and "+airf" for the additional low-noise airframe measures. The resulting vehicle variants of the 2018 study are summarized in Figure 7. Starting from the reference vehicle "zero", the selected technologies and design modifications are applied. On the left hand side, vehicles with conventional tube-andwing architecture are listed. In a first design modification (“+gtf”), the engine is simply replaced on board of the "zero"-resulting in vehicle "neo". In a second design iteration ("+adapt"), the vehicle 
layout is furthermore adapted to the GTF concept-leading to vehicle concept "neodapt". All three vehicles can furthermore be equipped with low-noise airframe technology (modification "+airf"). On the right hand side, the low-noise vehicle architectures are listed. The "V2 (af)" is based on the "zero"-also with conventional enginesbut significantly modified in order to shield the engine fan noise ("+shield"). The shielding concept and vehicle architecture is based on previous findings from a large design study, see Ref. ${ }^{31}$. The second low-noise vehicle is a new design referred to as "fanex". This vehicle with fan noise shielding ("+shield") is furthermore equipped with GTF engines ("+gtf") and is adapted to this new engine concept ("+adapt"). Both low-noise vehicles are directly equipped with lownoise airframe technology ("+airf"). The layouts of aircraft design "zero", "neopdapt", "V-2 (af)", and "fanex" are depicted in the Appendix (Figures 1-3).
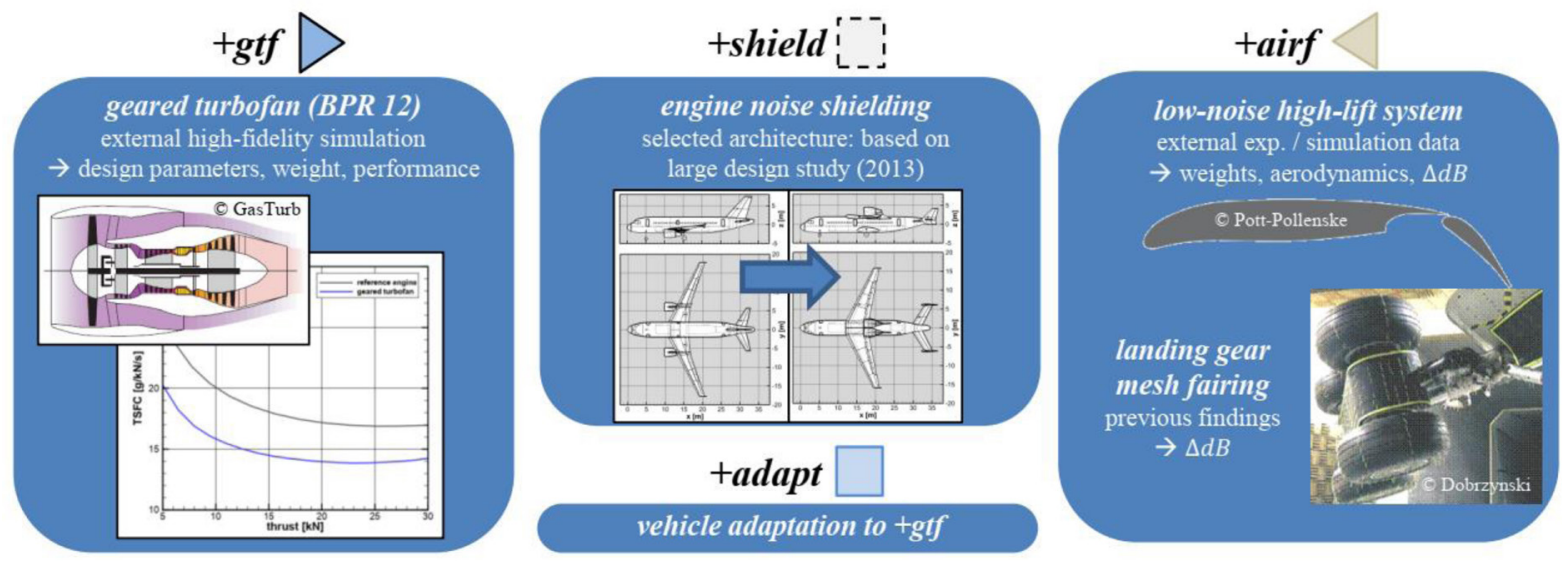

Figure 6 Selected technologies for engine (“+gtf”), architecture (“+adapt", “+shield”), and airframe (“+airf”).

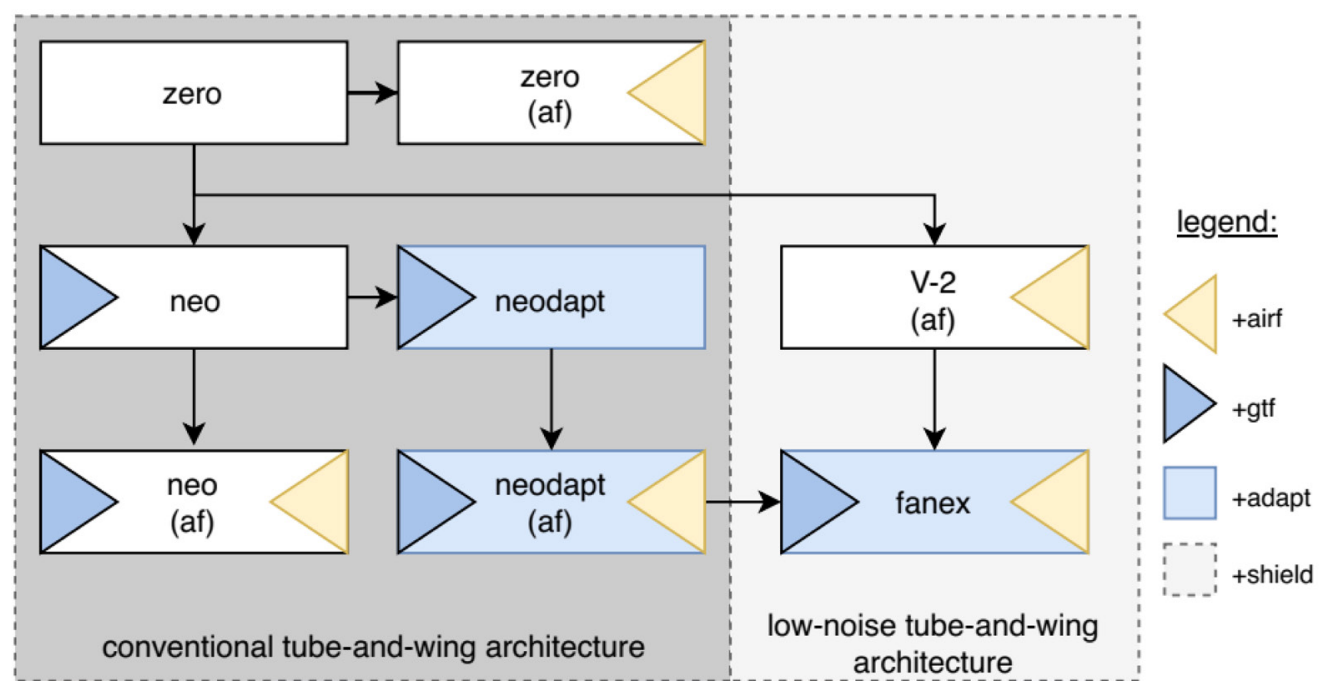

Figure 7 Vehicle concepts and applied technologies.

\section{Impact of engine replacement on performance and noise}

To directly investigate the impact of an engine replacement, comparative assessments of conventional vehicles, i.e., "zero" vs. "neodapt", and low-noise vehicles, i.e., "V2 (af)" vs. "fanex", are presented. Replacing the reference engine of BPR 6 with a geared turbofan engine of BPR 12 has significant implications on the fuel requirements along the design mission. A significantly reduced fuel requirement along the design mission is further exploited by adapting the aircraft design accordingly. The transported fuel mass on board is reduced according to the fuel requirement and consequently less fuel tanks are installed. Maintaining a constant wing loading directly enabled a reduction of wing area and consequently a down-sizing of the tail. Iteration of the PrADO design modules accounted for several side effects, e.g., downsizing of the landing gear, which furthermore reduced the overall aircraft weight. In summary, the adaption of the aircraft design results in the following changes to key design and performance parameters of the reference aircraft "zero": wing area $-8.1 \%$, maximum take-off weight $-7.5 \%$, operational empty weight $-2.7 \%$, design mission fuel requirement $-27.1 \%$, and the direct operating costs per flight $-7.7 \%$. These modifications ("+adapt") are relevant for vehicles "neodapt" and "fanex". Overall, the Direct Operating Consts (DOC) per flight can be reduced by almost $8 \%$ if the reference engine is replaced by the BPR 12 engine and the vehicle is adapted. This cost reduction is almost constant for the engine replacement onboard of the conventional and low-noise vehicles. 
A detailed assessment of the engine noise emission for the reference and the BPR 12 engine show a significant noise reduction potential for the engine replacement. The effect on vehicle noise immission and flight performance is a direct prediction result of the simulation process comprised of PrADO, SHADOW, and PANAM. The airframe measures are accounted for by modifying the available airframe noise sources within PANAM. The new high-lift concept and the selected landing gear mesh fairing are accounted for by subtracting specified and constant level differences $\Delta \mathrm{dB}$ from the corresponding PANAM emission spectra of each specific component. The low-noise droop nose is accounted for by $-6 \mathrm{~dB}$ and the trailing edge modifications by $-5 \mathrm{~dB}$ with respect to the PANAM predictions, respectively. Furthermore, the impact on the component weight and aerodynamic performance is accounted for in PrADO hence has a direct impact on the aircraft flight performance along the entire flight, i.e., including approach and departure, see Refs. ${ }^{23,24}$ for more details. The landing gear mesh fairing is approximated by $-3 \mathrm{~dB}$ delta with respect to the PANAM predictions for the landing gear. For this modification, only the level difference has been accounted for and any potential implication on landing gear drag or increased weight is assumed to be of neglectable relevance.

According to the introduction, the SEL isocontour areas were selected here. Figure 8(a) shows the significantly different isocontour areas for "zero" and "neodapt", the two vehicles with the conventional architecture as depicted in Appendix (Figure 1\&2). Isocontour areas are mainly reduced due to the engine replacement ("+gtf"). Further reduction can be achieved by the aircraft design modification ("+adapt") and altered flight performance of the "neodapt". The reduced weight and thrust excess due to the BPR 12 engine enables a steeper and faster climb out of the "neodapt" compared to the "zero". A similar observation can be made for the low-noise aircraft architectures as depicted in Figure 3 and Figure 4. Figure 8(b) also shows a significant area reduction despite the fact that both vehicles are already designed for low-noise, i.e., the fan noise is already effectively shielded. For both aircraft architectures the engine replacement ("+gtf") is most promising toward reduction of noise isocontours along departure and approach procedures.

\section{Detail assessment of level differences}

In contrast to the baseline study, ${ }^{35}$ a detailed assessment of level differences-including prediction uncertainties-due to the modifications is presented here. Two specific observers have been selected for further investigation. These observers are intentionally not placed at the certification points but at 6 and $15 \mathrm{~km}$ after brake-release (marked with white symbols in Figures 8(a) and 8(b)) which is a much more representative situation with respect to community noise annoyance around any major airport.

For the "neodapt" significant level reductions compared to the reference vehicle "zero" are predicted, i.e., due to "+gtf" and "+adapt". Significant level reductions can be found in all major noise metrics: SEL and $\mathrm{L}_{\mathrm{A}, \max }$ (mainly due to jet noise reduction), and EPNL (mainly due to fan noise reduction), see Table 1. A significant benefit can also be identified for an engine replacement onboard of the lownoise vehicles, i.e., comparing "V-2 (af)" and "fanex". The levels are significantly reduced for the "fanex", see Table 1, but the EPNL differences are less pronounced compared to the differences among the vehicles with a conventional architecture. This can directly be attributed to an already prevailing fan noise reduction due to shielding effects and therefore lesser dominance of the tonal fan noise. It can furthermore be demonstrated that the engine replacement significantly increases the importance and effectiveness of any low-noise measure to the airframe ("+airf"). This is obviously a very important finding for the noise immission associated with typical approach situations (no isocontour areas are displayed here but the interested reader is referred to Ref. ${ }^{35}$ for more detail).

Table I Influence of engine replacement on noise: conventional ("neodapt" vs. "zero") and low-noise aircraft architectures ("fanex" vs. "V-2 (af)")

\begin{tabular}{lllll}
\hline & \multicolumn{2}{c}{$\Delta$ (neodapt-zero) } & \multicolumn{2}{l}{$\Delta($ fanex-V-2(af) $)$} \\
\cline { 2 - 5 } case/metric & $\mathrm{x}=6 \mathrm{~km}$ & $\mathrm{x}=15 \mathrm{~km}$ & $\mathrm{x}=6 \mathrm{~km}$ & $\mathrm{x}=15 \mathrm{~km}$ \\
\hline $\mathrm{L}_{\mathrm{A}, \max }[\mathrm{dB}]$ & -3.5 & -4.9 & -4.1 & -3.0 \\
EPNL [dB] & -6.2 & -5.8 & -4.1 & -2.8 \\
SEL [dB] & -3.1 & -3.1 & -3.5 & -2.3 \\
\hline
\end{tabular}

To specifically identify the effect of the applied low-noise measures "+gtf", "+adapt", "+airf", and "+shield", the level differences in $\mathrm{L}_{\mathrm{A}, \max }$ are further assessed. The uncertainty assessment as introduced in Refs. ${ }^{36,37}$ is then applied to these predicted level differences. Now the effect of each measure can be assessed under consideration of the known prediction uncertainties. The departure flight scenario as described above is assessed here but a detailed investigation of an approach is furthermore included to directly compare the different low-noise measures.

The three contributors to the overall uncertainty of the predicted immission are input uncertainty, modeling uncertainty, and propagation uncertainty. The input parameter uncertainty is negligible compared to the modeling and propagation uncertainty for this application. The input data comes with only very small uncertainties because it is generated by high-fidelity simulation or comes from experimental data, i.e., airframe and engine noise data. For the modeling uncertainties of the applied noise source models, the following values are assumed.

a. airframe noise sources

- Landing gear \& high-lift: $\mathrm{u}_{\text {mod }}$ of $1.4 \mathrm{~dB}$

- Other airframe sources: $\mathrm{u}_{\text {mod }}$ of $1 \mathrm{~dB}$

b. engine noise sources

- Reference fan: $u_{\text {mod }}$ of $3.6 \mathrm{~dB}$ (including an additional $\mathrm{u}_{\text {mod }}$ of 3 $\mathrm{dB}$ due to fan noise shielding)

- Geared turbofan: $\mathrm{u}_{\text {mod }}$ of $4.2 \mathrm{~dB}$ (including an additional $\mathrm{u}_{\bmod }$ of 3 $\mathrm{dB}$ due to fan noise shielding)

- Jet: $\mathrm{u}_{\text {mod }}$ of $1.5 \mathrm{~dB}$

Yet, to assess level differences, covariances have to be included to account for correlated terms. A correlation factor of 0.8 is assumed here. A simple estimate for the uncertainties due to the propagation is included here as proposed in Schäffer et al..$^{59}$ and Thomann. ${ }^{60}$ The effect of propagation on the overall immission uncertainty becomes quiet large with increasing propagation distance. 


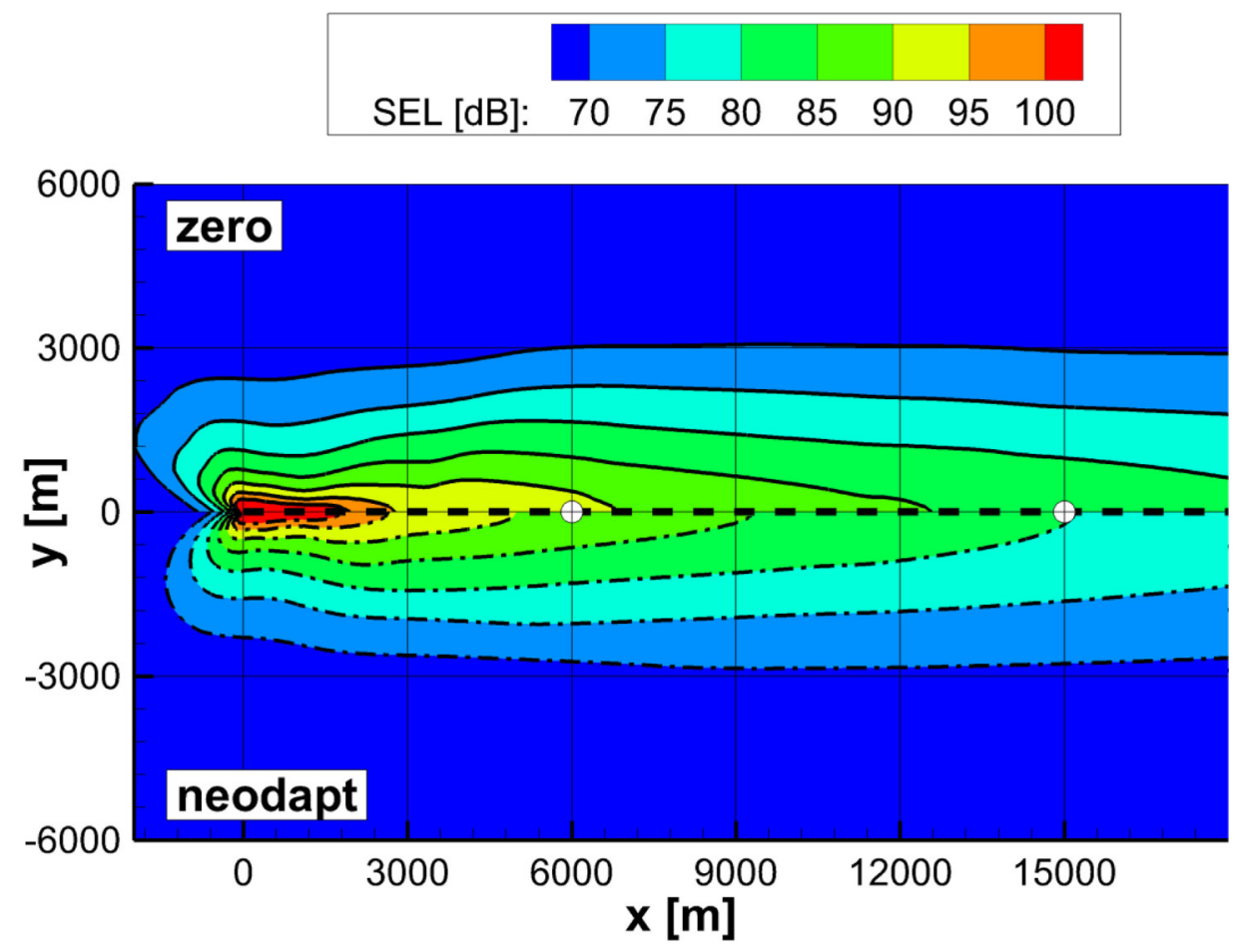

(a) Conventional aircraft architectures

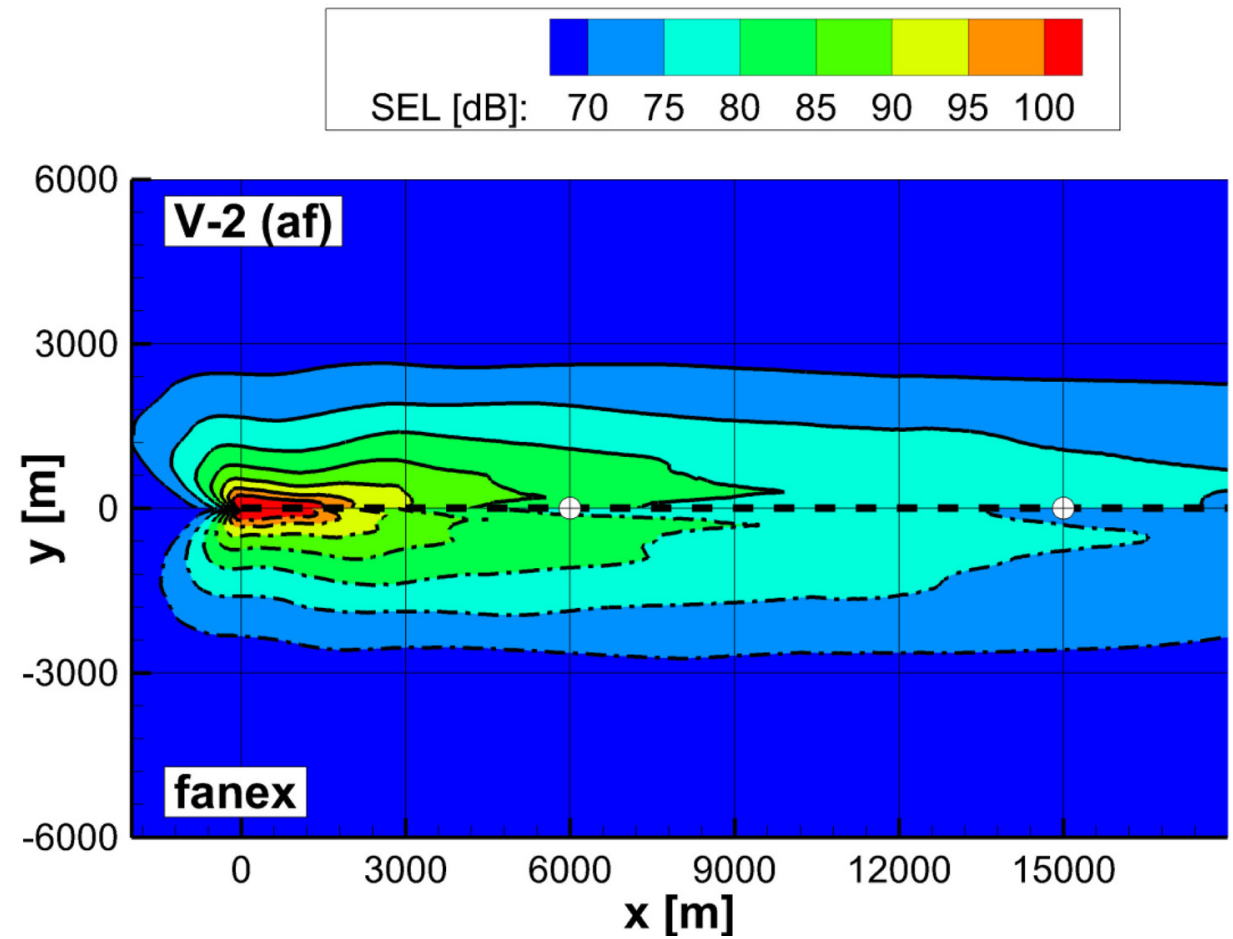

(b) Low-noise aircraft architectures

Figure 8 SEL contours along simulated departure: Influence of engine replacement for different aircraft architectures. 
Figure 9 shows the level differences at each observer location relative to the reference aircraft "zero" due to selected measures as depicted in Figure 6, i.e., "+gtf", "+airf", and "+shield". Different colors for the bar plots have been selected intentionally in order to emphasize the fact that each bar plot represents either an approach (green) or a departure (red) situation hence to avoid a direct comparison of the two situations.

Figure 9(a) shows $3.4 \pm 1.9 \mathrm{~dB}$ level reduction compared to the reference if the engine is replaced and the vehicle is adapted ("+gtf" and "+adapt"), i.e., a comparison of vehicles "zero" and "neodapt". At $15 \mathrm{~km}$ distance a level reduction of $4 \pm 1.7 \mathrm{~dB}$ is predicted, see Figure 9(b). Even if predicted uncertainties for the "+gtf" modification are taken into account, the level differences are significant compared to the reference. As expected, the additional low-noise airframe ("+airf") does not have any significant effect on the noise immission along the departure. If the aircraft architecture is furthermore modified to exploit fan noise shielding ("+shield") a tremendous reduction between $11.4 \pm 1.7$ and $14.9 \pm 2.5 \mathrm{~dB}$ is predicted at 6 and $15 \mathrm{~km}$ distance, respectively. Even consideration of prediction uncertainties will yield significant noise reduction potential at both observer locations along the departure.

For the approach case, depicted in Figures 9(c) and 9(d), low-noise measures to the airframe ("+airf") are more effective due to airframe noise relevance. The engine replacement still yields $3.0 \pm 1.8 \mathrm{~dB}$ level reduction at the further observer location compared to the reference see Figure 9(c). This can be attributed to the significant reduction of prevailing fan noise contribution associated with the "zero". With this reduction, it becomes very efficient to further reduce the now dominating airframe noise. The "+airf" measures reduce the noise immission by $7.5 \pm 1.9 \mathrm{~dB}$ at the further observer location; see Figure 9(c). The effect of " $+\mathrm{gtf}$ " at the closer observer is still significant but reduced to a level reduction of $1.1 \pm 2.2 \mathrm{~dB}$, see Figure 9(d). This is due to the now dominating landing gear contribution which can furthermore be reduced by $3 \mathrm{~dB}$ for the "+airf" measures, i.e., resulting in an immission reduction of $4.0 \pm 2.2 \mathrm{~dB}$ at $6 \mathrm{~km}$ before touch-down. For the approach case, a smaller effect of engine noise shielding can be observed due to the more dominating airframe noise contribution. At the most distant observer location, the noise reduction due to "+shield" is less than $0.5 \mathrm{~dB}$ compared to the reduction that can be achieved by simply replacing the engine ("+gtf”). The closer observer is subject to more engine noise than the distant observer, hence more effect due to "+shield" is experienced. Taking uncertainties into consideration, no relevant level difference can be identified between "+shield" and "+gtf" for both observer situations along the approach.

The level differences and the associated uncertainties vary significantly along a simulated flight. Furthermore, the situation along an approach is obviously significantly different to a departure situation. Multiple observer locations have to be considered in order to draw any final conclusions of novel technologies. For the presented application case it is demonstrated that the combination of engine replacement (“+gtf”), vehicle adaptation (“+adapt”), and noise shielding ("+shield") is most promising toward future low-noise aircraft concepts. Significantly reducing the engine noise contribution makes measures to the airframe ("+airf") especially effective during approach.

The application example clearly indicates that a low-noise aircraft design can only be identified by a detailed immission analysis within the design process rather than by subsequent noise assessment of final vehicle designs. For example, optimizing the noise emission of a highlift concept with only a subsequent noise immission assessment will not result in an optimal low-noise aircraft design. ${ }^{23,24}$ Furthermore, no conclusion of results should be drawn if relevant snowball effects are not considered. For example, modification of engine bypass ratio and assessment of the noise immission without proper modeling of the new engine performance is meaningless. If the impact of new technology on the flight performance is not accounted for in early design stages, it can be assumed that the final results might change dramatically according to a different thrust setting or flight velocity.

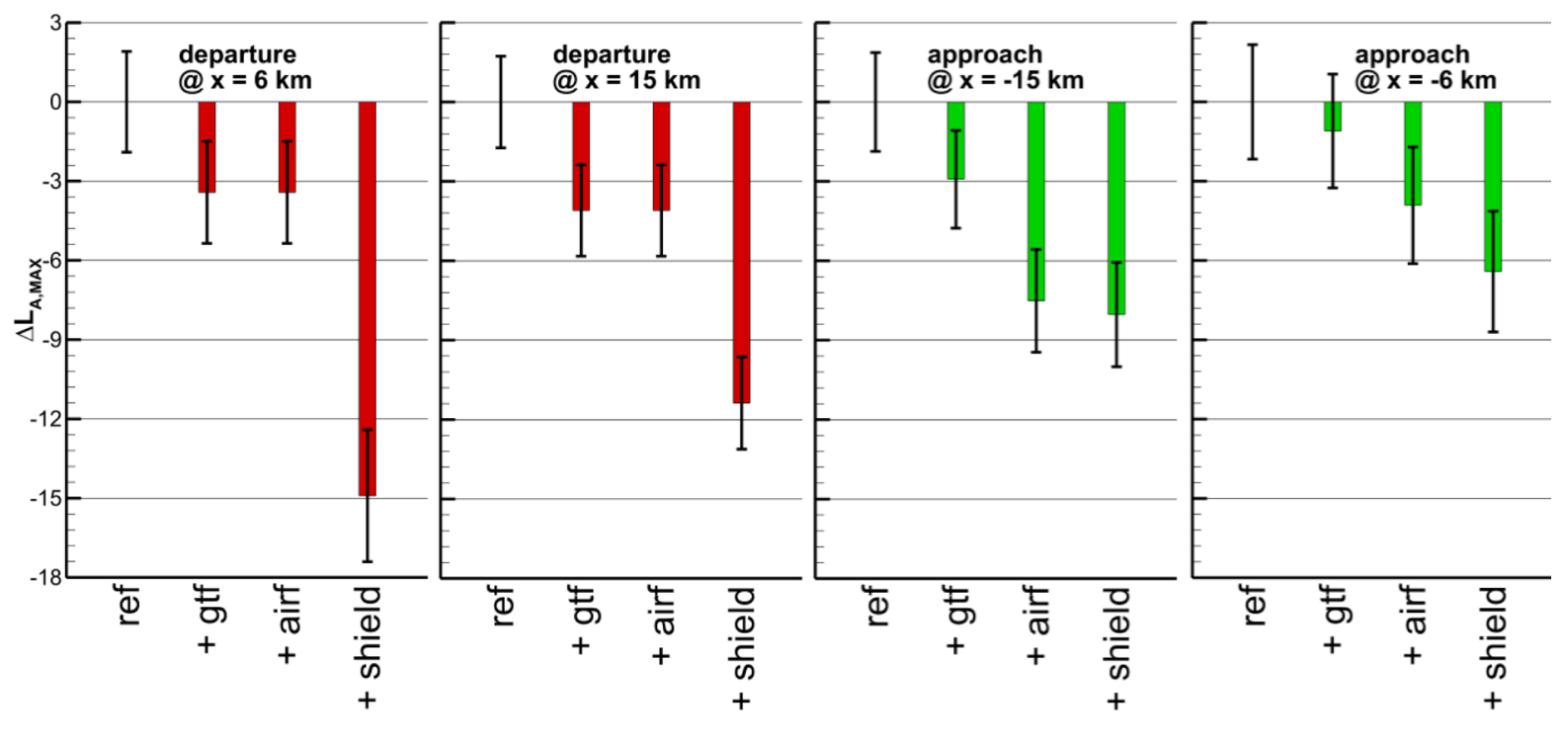

(a) dep at $x=6 \mathrm{~km}$

(b) dep at $x=15 \mathrm{~km}$

(c) app at $x=-15 \mathrm{~km}$

(d) app at $x=-6 \mathrm{~km}$

Figure 9 Influence of low-noise measures on $\Delta \mathrm{L}_{\mathrm{A}, \max }$ and associated uncertainty at selected observer locations along departure (dep) or approach (app) flight path. 


\section{Summary \& lessons learned}

DLR and TU BS have developed an aircraft design synthesis process with integrated noise prediction capabilities. Before the joint activity, acoustic assessment was not available within conceptual aircraft design but had to be applied as a subsequent noise assessment of predefined concepts. As a consequence, the potential solution space was henceforth significantly restricted. The noise of existing and future aircraft can now be predicted as early as within the conceptual design phase - at the moment the application is limited to tube-andwing architectures. For a comprehensive immission prediction, vehicles are simulated along individual flight trajectories which can be subject to low-noise optimization as well. Already in the design phase of novel and non-existing vehicles and technologies, it is now possible to identify promising flight trajectories for minimum noise immission. To avoid a partial and incomplete assessment, multiple metrics are evaluated for arbitrary arrays of observers. The engine installation effects are accounted for by a specific DLR simulation tool, SHADOW, but simulation results of higher fidelity can be implemented and processed as well. Dedicated interfaces enable a direct consideration of external input data within the PrADO simulation process, e.g., by consideration of modified aircraft/engine design, and within the noise prediction with PANAM, e.g., consideration of delta levels for selected noise sources. The overall process is under constant development. New findings with respect to engine noise shielding simulation are implemented as well as advanced noise source models such as the new DLR fan noise model PropNoise, see Ref. ${ }^{63}$ Advanced concepts such as distributed propulsion or Boundary Layer Ingestion (BLI) require additional research activities since no mature models are available yet. The overall process has been subject to an uncertainty assessment. So far, focus of the uncertainty assessment lies on conventional tube-and-wing architectures but will be updated with recent findings of novel technologies and concepts.

Several lessons learned can be documented for the last 10 years of the joint research. The most important lesson learned is to ensure the completeness of considered disciplines and relevant interactions. An adequate noise immission assessment cannot be limited to the emission situation, to certain aircraft or engine components, to specific noise metrics, nor to a fixed operating condition. It is recommended to ultimately assess the immission along typical flight procedures at multiple observer locations and evaluating multiple noise metrics in order to draw any conclusion with respect to novel technologies.

An absolute must-have for any feasible noise prediction is a highquality simulation of the thermodynamic engine cycle that includes a sufficiently accurate modeling of aerodynamics. No adequate input data for any noise prediction should be solely based on simplified methods and tools. It is demonstrated that these engine parameters have a huge influence on the predicted noise, see Figure 1 for some exemplary parameters. Another absolute must-have is access to FDR when comparing predictions with fly-over measurements. Without the precise knowledge of at least the most dominating parameters, i.e., the high-lift and landing gear positions, the flight velocity, and the thrust setting, no such comparison should be initiated. An estimation of the achievable level of agreement between simulation and measured noise levels can be added to the lessons learned. A perfect agreement is considered as a pure coincidence because of several shortcomings inherent for any overall noise prediction, i.e., not capturing scaling laws, insufficient modeling capabilities, and oversimplification of geometries. The best agreement can be expected for maximum levels or comparative analyses in general (trend assessment). ${ }^{64-66}$

Future activities will focus on electrification among other topics. A first step towards the assessment of such electric aircraft is the revisit of propeller noise simulation capabilities. The implemented noise source models have to be assessed for their applicability toward new aircraft concepts with modern turboprop engines and installation effects that will distort the inflow. It can be expected that electrification of the propulsion system might result in significantly different approach procedures due to a now possible engine-out option compared to the flight-idle of conventional turbofan engines or maybe even by enabling wind-milling to recharge the energy storage on board.

Furthermore, the new perception influenced design activities with Empa will be continued with a focus on novel vehicles and unconventional flight procedures. The main focus of the future work lies on a feedback loop from listening tests back to the noise modeling and aircraft definition. The results of these listening tests can ultimately be used to improve the overall prediction capabilities.

\section{Acknowledgments}

The authors highly appreciate the support of several colleagues and students at DLR and Empa over the years. Special thanks go to former students Philip Krammer (2008), Christopher Kott (20092010), and Raihan Ramdjanbeg (2014-2015). Furthermore, the authors thank Joshua Ammermann for his contribution as student employee (2016 - today). PhD students Jason Blinstrub (2014-today) and Marc Koch (2016-today) contribute significantly to the ongoing development and their work and effort toward low-noise aircraft design research activities is highly appreciated. The authors are very grateful for the scientific support of the following DLR colleagues: Werner Dobrzynski (retired), Tom Otten, Florian Wolters, Michael Pott-Pollenske, and Karl-Stephane Rossignol. The expertise and support of Empa colleagues Beat Schäffer and Reto Pieren toward uncertainty assessment and auralization of the noise prediction results is greatly appreciated.

\section{Conflicts of interest}

Authors declare that there is no conflict of interest. 


\section{Appendix}
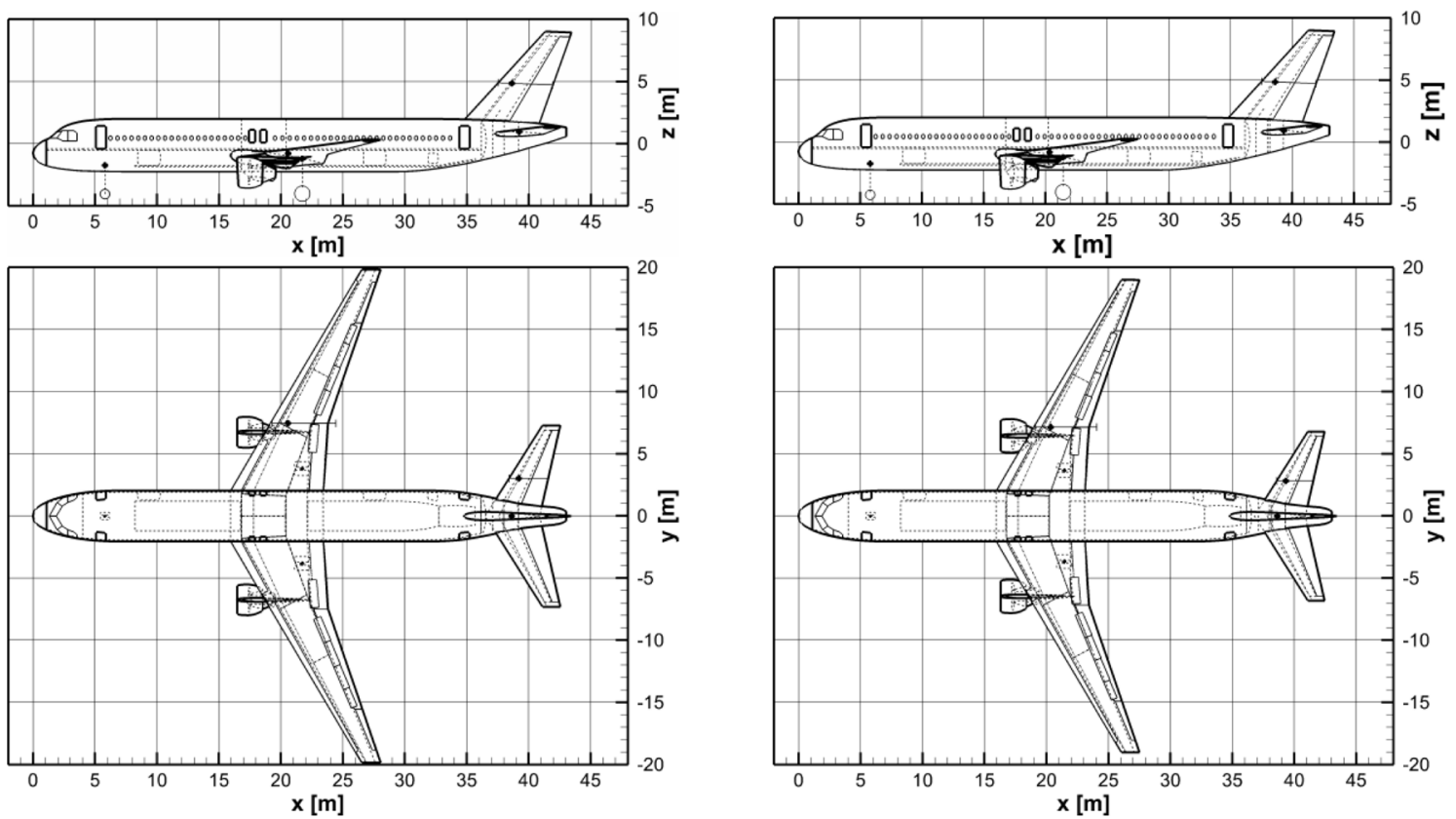

Figure 1 Vehicle design "zero". 35

Figure 2 Vehicle design "neodapt". ${ }^{35}$
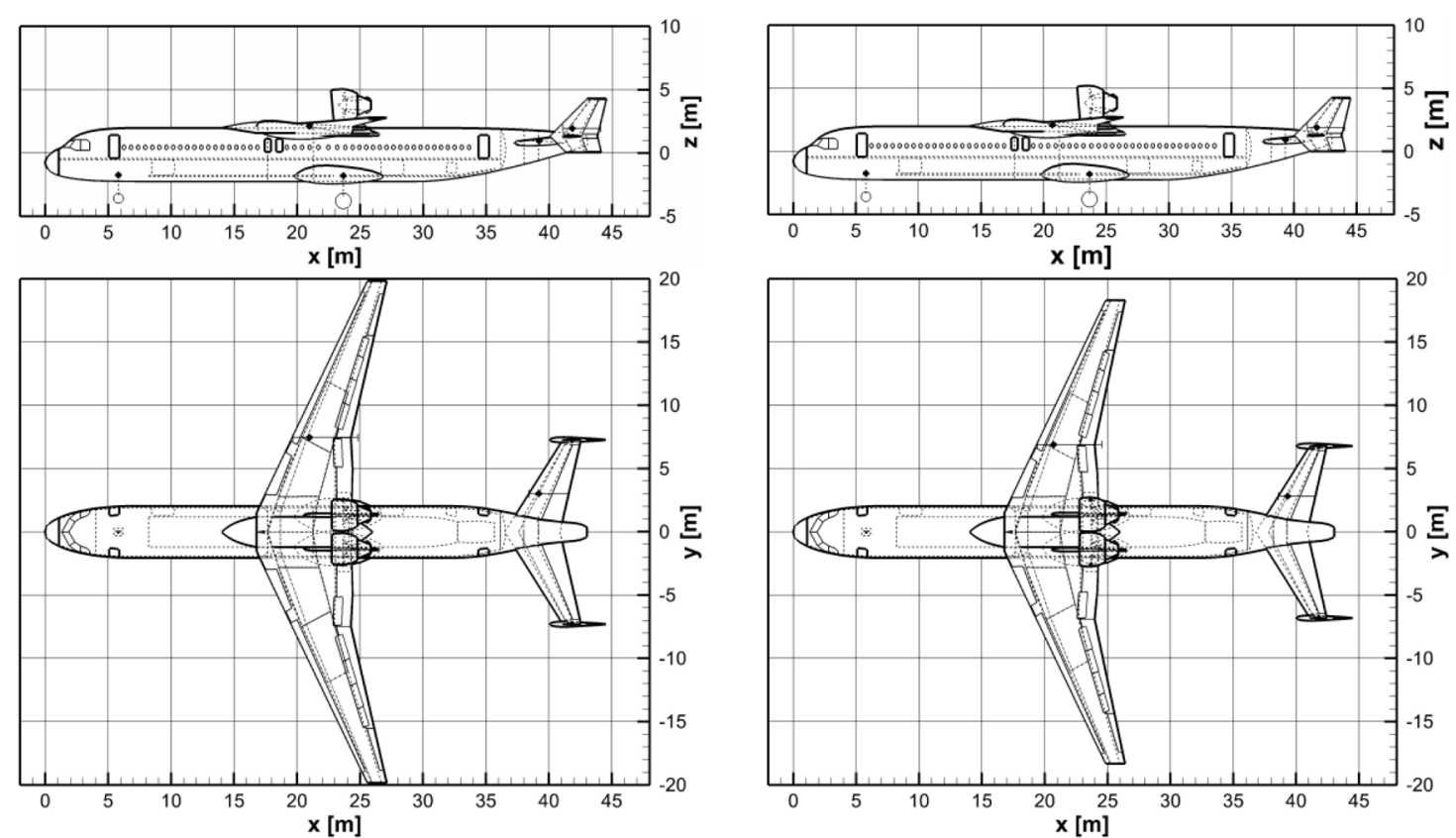

Figure 3 Vehicle design "V-2 (af)",35

Figure 4 Vehicle design "fanex". 35 


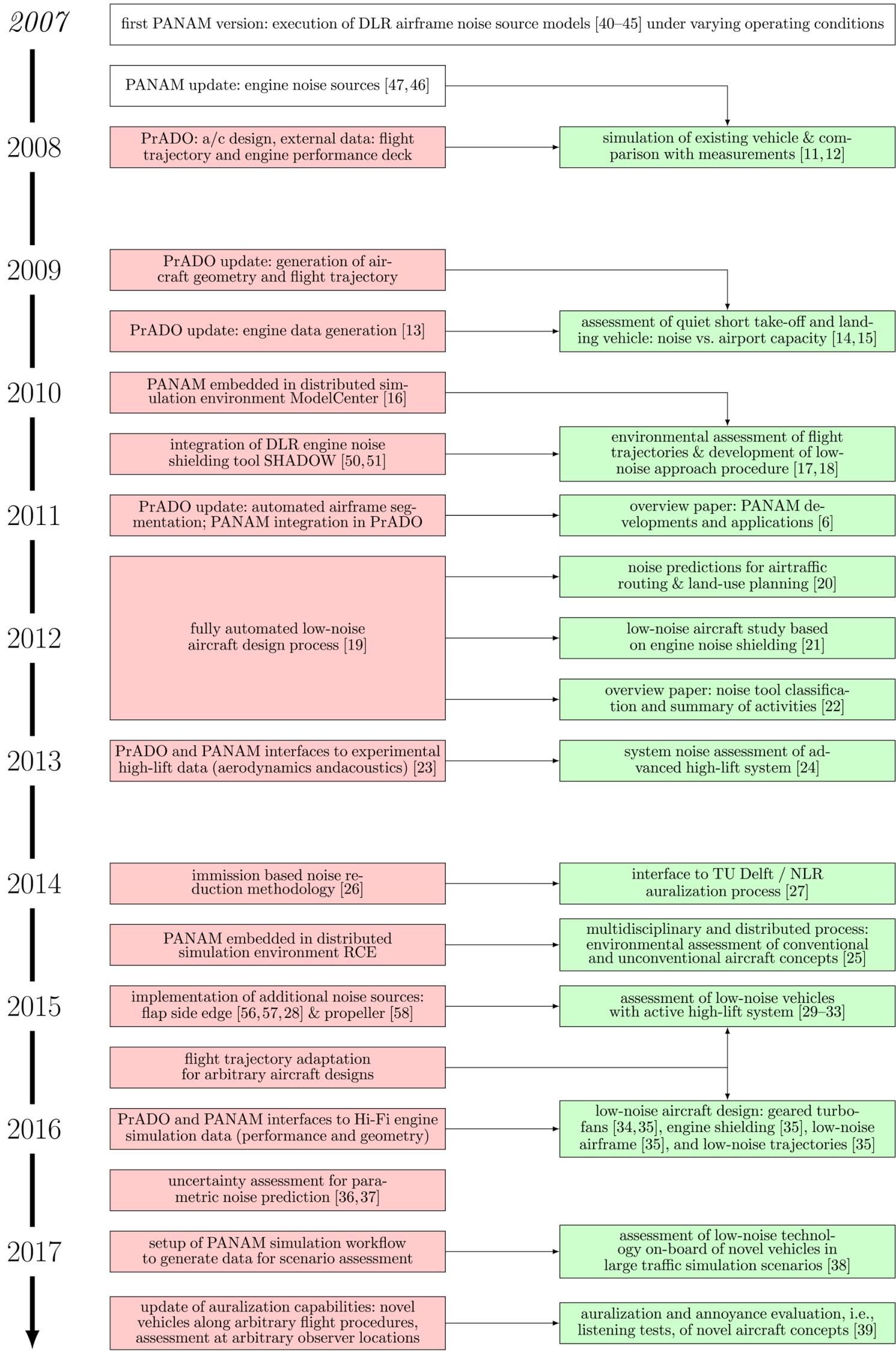

Figure 5 Timeline of developments (red boxes) and applications (green boxes) with literature allocation. 


\section{References}

1. Concept of a balanced approach principle to aircraft noise management. Appendix C of Assembly Resolution A35, ICAO; 2007.

2. Bundesministerium der Justiz: Erste Verordnung zur Durchfuehrung des Gesetzes zum Schutz gegen Fluglaerm (Verordnung ueber die Datenerfassung und das Berechnungsverfahren für die Festsetzung von Laermschutzbereichen - 1.FlugLSV), Bundesgesetzblatt BGBl I; 2008.

3. Olmstead JR, Fleming GG, Gulding JM, et al. Integrated Noise Model (INM) Version 6.0. Technical Manual, U.S. Department of Transportation Federal Aviation Administration: Washington DC, USA; 2002

4. Bridges J, Khavaran A, Hunter CA. Assessment of Current Jet Noise Prediction Capabilities. 14th AIAA/CEAS Aeroacoustics Conference: Vancouver, British Columbia Canada; 2008

5. Envia E, Tweedt DL, Woodward RP, et al. An Assessment of Current Fan Noise Prediction Capability. 14th AIAA/CEAS Aeroacoustics Conference: Vancouver, British Columbia Canada; 2008.

6. Bertsch L, Guerin S, Looye G, et al. The Parametric Aircraft Noise Analysis Module - status overview and recent applications. 17th AIAA CEAS Aeroacoustics Conference: Portland, Oregon, USA; 2011.

7. Heinze W. Ein Beitrag zur quantitativen Analyse der technischen und wirtschaftlichen Auslegungsgrenzen verschiedener Flugzeugkonzepte für den Transport großer Nutzlasten. ZLRForschungsbericht 94-01, ISBN 3-928628-14-3.

8. Heinze W, Oesterheld CM, Horst P. Multidisciplinary aircraft design process PrADO - Program design and application in the context of aircraft concept studies. DLRK: Germany; 2001.

9. Werner-Westphal W, Heinze W, Horst P. Multidisciplinary Integrated Preliminary Design Applied to Unconventional Aircraft Configurations. Journal of Aircraft. 2008;45(2):581-589.

10. Antoine N, Kroo I, Willcox K, et al. A Framework for Aircraft Conceptual Design and Environmental Performance Studies. 10th AIAA/ISSMO Multidisciplinary Analysis and Optimization Conference: Albany, New York, USA; 2004.

11. Bertsch L, Dobrzynski W, Guerin S. Tool development for LowNoise Aircraft Design. 14th AIAA/CEAS Aeroacoustics Conference: Vancouver, British Columbia, Canada; 2008.

12. Bertsch L, Dobrzynski W, Guerin S. Tool Development for Low-Noise Aircraft Design. Journal of Aircraft. 2010;47(2):694-699.

13. Krammer P, Bertsch L, Werner-Spatz C. Multidisciplinary Preliminary Aircraft Design with Integrated Noise Analysis Capabilities. DLR: Hamburg, Germany; 2009.

14. Bertsch L, Schneider O, Hemmer H, et al. Process Implementation for the System Evaluation of new Low-Noise STOL Transportation Concepts. Paper No. 2, CEAS/KATnet II Conference on Key Aerodynamic Technologies: Bremen, Germany; 2009

15. Schneider O, Kreth S, Bertsch L. Towards a Quiet Short Take-Off and Landing Transportation System: Concept Evaluation and ATM Integration. International Powered Lift Conference: Philadelphia, USA; 2010 .

16. Bachmann A, Kunde M, Litz M, et al. Automation of Aircraft Pre-design Using a Versatile Data Transfer and Storage Format in a Distributed Computing Environment. 3rd International Conference on Advanced Engineering Computing and Applications in Sciences; 2009.

17. Bertsch L, Looye G, Otten T, et al. Integration and application of a tool chain for environmental analysis of aircraft flight trajectories. 9th AIAA Aviation Technology, Integration and Operations Conference: Hilton Head Island, South Carolina, USA; 2009.
18. Bertsch L, Looye G, Anton E, et al. Flyover Noise Measurements of a Spiraling Noise Abatement Approach Procedure. Journal of Aircraft. $2011 ; 48(2): 436-448$

19. Bertsch L. Noise Prediction within Conceptual Aircraft Design. DLR Forschungsbericht; 2013. $184 \mathrm{p}$

20. Toebben HH, Mollwitz V, Bertsch L, et al. Flight Testing of Noise Abating RNP Procedures and Steep Approaches. Journal of Aerospace Engineering. SAGE Publications Ltd; 2013.

21. Bertsch L, Heinze W, Lummer M. Application of an Aircraft Design-ToNoise Simulation Process. 14th AIAA Aviation Technology, Integration, and Operations Conference: Atlanta, Georgia, USA; 2014.

22. Bertsch L, Isermann U. Noise prediction toolbox used by the DLR aircraft noise working group. Inter Noise Conference: Innsbruck, Austria; 2013.

23. Wicke K, Bertsch L. SLED-Silent Leading Edge Devices, Final Report on Aircraft Design and Systems Analysis. Institute of Air Transport Systems: Hamburg; 2013.

24. Pott-Pollenske M, Wild J, Bertsch L. Aerodynamic and Acoustic Design of Silent Leading Edge Devices. 20th AIAA/CEAS Aeroacoustics Conference: Atlanta, Georgia, USA; 2014.

25. Pfeiffer T, Moerland E, Freund S, et al. Ergebnisse des Flugzeugvorentwurfprojekts FrEACs (FutuRe Enhanced Aircraft ConfigurationS). DRLK: Muenchen, Germany; 2017.

26. Blinstrub J, Bertsch L. Towards an Immission-Based Noise Reduction Method for Conceptual Aircraft Design. Notes on Numerical Fluid Mechanics and Multidisciplinary Design New Results in Numerical and Eperimental Fluid Mechanics X. Springer International Publisher: Switzerland; 2016. 687-697 p.

27. Arntzen M, Bertsch L, Simons D. Auralization of novel aircraft configurations. 5th CEAS Air \& Space Conference: Delft, Netherlands; 2015. $11 \mathrm{p}$.

28. Ramdjanbeg R, Bertsch L, Rossignol KS, et al. Flap Side-Edge Noise Prediction within Conceptual Aircraft Design. Notes on Numerical Fluid Mechanics and Multidisciplinary Design New Results in Numerical and Eperimental Fluid Mechanics X. Springer International Publisher: Switzerland; 2016. 731-742 p.

29. Bertsch L, Heinze W, Lummer M. Towards the System Noise Assessment of SFB 880 Vehicle Concepts. SFB 880- Fundamentals of high-lift for future commercial aircraft: Biennial Report, Braunschweig; 2015.

30. Blinstrub J, Heinze W, Bertsch W, et al. System noise assessment of an aircraft with coanda flaps. READ Conference; 2016. 12-14 p.

31. Blinstrub J, Bertsch L. System noise assessment of SFB 880 concepts, SFB 880- Fundamentals of high-lift for future commercial aircraft: Biennial Report. Braunschweig; 2017. 187-196 p

32. Radespiel R, Heinze W, Bertsch L. High-Lift Research For Future Transport Aircraft. DLRK: Muenchen, Germany; 2017.

33. Blinstrub J, Bertsch L, Heinze W. Assessment of the Noise Immission along Approach and Departure Flightpaths for Different SFB880 Vehicle Concepts. AIAA Aviation Forum, American Institute of Aeronautics and Astronautics: Atlanta, Georgia, USA; 2018.

34. Giesecke D, Lehmler M, Friedrichs J, et al. Evaluation of Ultra-High Bypass Ratio Engines for an Over-Wing Aircraft Configuration. Journal of the Global Power and Propulsion Society; 2018.

35. Bertsch L, Wolters F, Heinze W, et al. System noise assessment of a tube-and-wing aircraft with geared turbofan engines. AIAA Aerospace Sciences Meeting; 2018.

36. Bertsch L, Schäffer B, Guerin S. Towards an uncertainty analysis for 
parametric aircraft system noise prediction. 12th ICBEN congress on noise as a public health problem: Zurich, Switzerland; 2017. 12 p.

37. Bertsch L, Schäffer B, Guerin S. Uncertainty analysis for parametric aircraft system noise prediction. Journal of Aircraft. 2018;56(2):529544.

38. Delfs J, Bertsch L, Zellmann C, et al. Aircraft noise assessment-From single components to large scenarios. Energies. 2018;11(2):429-429.

39. Pieren R, Bertsch L, Blinstrub J, et al. Simulation process for perceptionbased noise optimization of conventional and novel aircraft concepts. Aerospace Sciences Meeting; 2018. 8-12 p.

40. Dobrzynski W, Chow LC, Guion P, et al. A European Study on Landing Gear Airframe Noise Sources. 6th AIAA/CEAS Aeroacoustics Conference: La-haina Hawaii/USA; 2000.

41. Dobrzynski W, Chow LC, Guion P, et al. Research into Landing Gear Airframe Noise Reduction. AIAA-2002-2409, 8th AIAA/CEAS Aeroacoustics Conference: Breckenridge, USA; 2002.

42. DLR: Entwicklung von Quellmodellen für den Umstroemungslaerm von Verkehrsflugzeugen durch Auswertung von Windkanal-Messdaten und Ueberflugmessungen an einem Airbus A319 - Arbeiten im Rahmen des Projekts LAnAb. Abschlussbericht für den BMFT, DLR IB 124-2006/05.

43. Pott-Pollenske M, Dobrzynski W, Buchholz H, et al. Airframe Noise Characteristics from Flyover Measurements and Predictions. 12th AIAA/CEAS Aeroacoustics Conference: Cambridge, Massachusetts, USA; 2006.

44. Dobrzynski W. Konfigurationen 2020 Abschlussbericht - Konfigurative Lärmkriterien, final project report. Ref. no.: K2020-DLR-000-017-P4Final Report, Braunschweig, Germany; 2007.

45. Dobrzynski W, Chow LC, Smith M, et al. Experimental Assessment of Low Noise Landing Gear Component Design. 15th AIAA/CEAS Aeroacoustics Conference: Miami, Florida, USA; 2009.

46. Heidmann MF. Interim prediction method for fan and compressor source noise. NASA Technical Report TM-X-71763; 1979.

47. Stone JR, Groesbeck DE, Zola CL. Conventional profile coaxial jet noise prediction. AIAA Journal. 1983;21(1):336-342.

48. Deidewig F. Ermittlung der Schadstoffemissionen im Unter- und Ueberschallug. German Aerospace Center, DLR: Forschungsbericht 9810, Collogne, Germany; 1998.

49. Koenig R, Heider J, Maierhofer M. Aircraft Flight Procedure Design with Respect to Noise Abatement as well as Economical and Pilot Workload Aspects. Inter-noise Congress and Exposition on Noise Control Engineering: Rio de Janeiro, Brazil; 2005.

50. Lummer M, Hepperle M, Delfs J. Towards a Tool for the Noise Assessment of Aircraft Configurations. Aeroacoustics of New Aircraft and Engine Configurations, 8th ASC-CEAS Workshop: Budapest, Hungary; 2004.
51. Lummer M. Maggi-Rubinowicz Diffraction Correction for Ray-Tracing Calculations of Engine Noise Shielding. 14th AIAA/CEAS Aeroacoustics Conference; 2008.

52. Rossignol KS, Pott-Pollenske M, Delfs J, et al. Investigating Noise Shielding by Unconventional Aircraft Configurations. 23rd AIAA/CEAS Aeroacoustics Conference; 2017.

53. Berton JJ. System Noise Prediction of the DGEN 380 Turbofan Engine. 21st AIAA/CEAS Aeroacoustics Conference; 2015. 22-26 p.

54. Sahai A, Wefers F, Pick S, et al. Interactive simulation of aircraft noise in aural and visual virtual environments. Applied acoustics. 2016;101:2438.

55. Rizzi SA, Auman AR, Lopes LV, et al. Auralization of hybrid wing-body aircraft flyover noise from system noise predictions. AIAA Journal of Aircraft. 2014;51(6):1914-1926.

56. Rossignol KS. Development of an empirical prediction model for flap-side edge noise. 16th AIAA/CEAS Aeroacoustics Conference: Stockholm, Sweden; 2010.

57. Rossignol KS. Empirical Prediction of Airfoil Tip Noise. 17th AIAA/ CEAS Aeroacoustics Conference: Portland, Oregon, USA; 2011.

58. Hanson DB. Helicoidal Surface Theory for Harmonic Noise of Propellers in the Far Field. AIAA Journal. 2012;18(10):1213-1220.

59. Schäffer B, Pluss S, Thomann G. Estimating the Model Specific Uncertainty of Aircraft Noise Calculations. Applied Acoustics. 2014;84:58-72.

60. Thomann G. Uncertainties of Measured and Calculated Aircraft Noise and Consequences in Relation to Noise Limits. The Journal of the Acoustical Society of America. 2007;123(5):32-49.

61. Zellmann C, Schäffer B, Wunderli JM, et al. Aircraft noise emission model accounting for aircraft flight parameters. Journal of Aircraft. 2017;55(2):682-695.

62. Rizzi S. Toward Reduced Aircraft Community Noise Impact via a Perception-Influenced Design Approach. Internoise. 2016;1-25.

63. Moreau A, Guerin S. The impact of low-speed fan design on noise: an exploratory study. Journal of Turbomachinery. 2016;138(8):081006.

64. Moreau A, Guerin S, Busse S. A method based on the ray structure of acoustic modes for predicting the liner performance in annular ducts with flow. NAG/DAGA International Conference on Acoustics; 2009. 4 p.

65. Becker R, Wolters F, Nauroz M, et al. Development of a gas tubine performance code and its application to preliminary engine design. Deutscher Luft- und Raumfahrtkongress; 2011. 27-29 p.

66. Wolters R, Becker R, Schnell P, et al. Engine performance simulation of the integrated V2527-Engine Fan. 54nd Aerospace Sciences Meeting, AIAA SciTech Forum: San Diego, USA; 2016. 4-8 p. 